\title{
FUN OR FRUSTRATION: MODELLING DISCONTINUANCE INTENTION OF SOCIAL MEDIA USERS
}

\author{
Shampa Rani Das \\ Daffodil International University \\ Shampa35-1009@diu.edu.bd \\ Imran Mahmud \\ Daffodil International University \\ imranmahmud@daffodilvarsity.edu.bd \\ Sharmin Ahmed \\ Daffodil International University \\ Sharmin.eee@diu.edu.bd \\ Siew Ching J-Ho \\ Universiti Sains Malaysia \\ Jhosc2015@gmail.com \\ Tarnima Warda Andalib \\ Universiti Sains Malaysia \\ Tarnimawarda.andalib@usm.my
}

\begin{abstract}
Excessive usage of social network services (SNS) can lead to exhaustion and frustration, which, in turn, can induce SNS discontinuance intention. In this study, the negative factors when using SNS are empirically tested. We constructed a research model that explores the effects of social overload, disclosure, and pattern of SNS use on SNS-induced exhaustion and frustration. We also examined the influence of exhaustion and frustration on SNS discontinuance intention. An empirical study of 170 SNS users from Bangladesh provides support for our hypotheses. Partial least squares algorithm is implemented to test the hypotheses. The result reveals significant influence of frustration on SNS discontinuance intention. The paper contributes by identifying several factors. Both theoretical and practical implications are discussed.
\end{abstract}

Keywords: Social Networking Services, Frustration, Facebook, Usage, Emotion, Information Technology.

\section{INTRODUCTION}

Initially Rogers introduced discontinuance for doing empirical research [1]. Emotions are defined as 'a mental state of readiness that arises from cognitive appraisals of events or thoughts' [2]. In the context of IT, the emotions become the behaviour of individuals through assessing an IT event [3]. Frustration occurs as a 
negative emotion when an individual is not able to satisfy a need due to an intervening obstacle [4]. Exhaustion of a user can turn into frustration; and continuous frustration as a negative emotion can lead to behaviours such as discontinuing the use of IT3. Facebook usage can lead to problems of attention distraction, poor time management, spending less time studying, and lower academic performance [5]. According to Facebook statistics, on an average, there were 728 million people on Facebook each day [6]. The study revealed that Facebook users were being frustrated after using this popular SNS [7]. Recently, Matt Ahlgren reported that on an average, there are 1.5 billion daily active Facebook users [8]. Their findings disclosed that frustration has been associated with Facebook dependence [9]. Due to usage difficulties, the users experienced frustration [10].

In the field of IT, frustration has been studied by some researchers pertaining to technology acceptance [11], [12]; the determinants of privacy beliefs [13]; and in the context of web site quality [14]. The antecedents of causing frustration were studied in the context of SNS6; however, the consequences of frustration were neglected. This study suggested more research on frustration in the context of IT usage3; Berger et al. also suggested more research on the negative effects while using SNS [15]. The people who are concerned about their privacy, later experience social media fatigue [16]. According to their evaluation, the users' discontinuance behaviour and social network fatigue are affected by social influence [17].

Hence, this research tried to fulfil the suggested idea from previous research with the research question, 'What are the antecedents and consequences of frustration when using SNS'? The researcher's aim was to find out the antecedents and consequences of frustration, besides finding out how far frustration actually influenced the discontinuance of SNS.

In the following sections, we first discuss the consequences of SNS discontinuance. Second, we develop a model and derive the hypotheses for its drivers and consequences. Third, using a study with 170 SNS Bangladeshi users, we empirically evaluate SNS discontinuance and the hypotheses. We then discuss the results, limitations, and implications for research and for practice.

\section{LITERATURE REVIEW AND MODEL DEVELOPMENT}

Frustration as a negative emotion can occur when using SNS and this negative emotion can foster behaviours such as discontinuing using SNS. The more an individual perceives social overload, the higher is his/her SNS discontinuous usage intention [18]. Thus, research on frustration in the context of SNS is necessary with the antecedents of social aspects such as:

\subsection{Social Overload}

Social overload is important for understanding the consequences of SNS discontinuous usage intention in terms of SNS-exhaustion and SNS-frustration. On Facebook, people care about their friends' social status, well-being, problems, achievements, and so on. Social overload is assumed as a negative impact of technology usage and that's why users feel exhausted with SNS; they also revealed that women experience higher levels of social overload than men because women are more involved and spontaneous in SNS activities [19], [20], [21]. Social overload is defined as a 
'negative perception of SNS usage when users receive too many social support requests and feel they are giving too much social support to others' [18]. According to Au et al and Maier et al., more social overload decreases an individual's level of SNS satisfaction [18], [22]. When users experience social overload, but their needs cannot be satisfied, it can influence the feeling of frustration. Thus, we hypothesise:

H1: Social overloading has a positive impact on frustration.

\subsection{Pattern}

Pattern replicates the users' behavioural patterns in responding to SNS activities [23]. Usually, users behave differently to coordinate with SNS events [24], [25], [26]. Hence, the variable pattern indicates that we have to inform friends about news prompts, communicate with friends periodically, and adapt communication patterns to use Facebook forcefully. This means a higher level of behavioural pattern leads to a higher level of SNS exhaustion. As a result, our proposed hypothesis is:

H2: Pattern has positive impact on SNS exhaustion.

\subsection{Disclosure}

The core view of disclosure is that virtual friends disclose a wealth of information on SNSs [27]. This study demonstrated that the variable disclosure can lead the users who are willing to process all this information to experience information overload [28]. Disclosure reflects a negative perception that too much information is disclosed on an SNS by oneself and one's virtual friends [26]. In this study, the variable disclosure reflects a threat on social status, pressure from friends to check status, information, friends' information and information seeking behaviour from friends. Consequently, we propose the third hypothesis based on our research model, which is:

H3: Disclosure has positive impact on SNS exhaustion.

\subsection{SNS Exhaustion}

The study reported that an excessive use of SNS has a positive impact on SNS exhaustion [29]. SNS-exhaustion reflects an individual's psychological reaction to stressors caused by using SNS [18], [30]. Thus SNS activities make people feel strained and stressed. An individual's psychological reaction indicates it as a stress condition and can be seen as frustration behaviour, and thus we hypothesise that:

H4: Exhaustion has positive impact on frustration.

\subsection{Frustration}

Frustration means that the needs of an individual could not be satisfied [4] and discontinuation reflects an individual's intention to stop using an SNS [31], [32]. The construct discontinuous usage intention describes an individual's intention to change his or her behaviour by no longer using a technology [18]. Negative emotions in the context of SNS were found to positively influence the intention to discontinue using a technology [19], [33]. Therefore, we hypothesise the following: 
H5: Frustration has positive impact on discontinuation.

Our proposed research model is shown in figure 1.

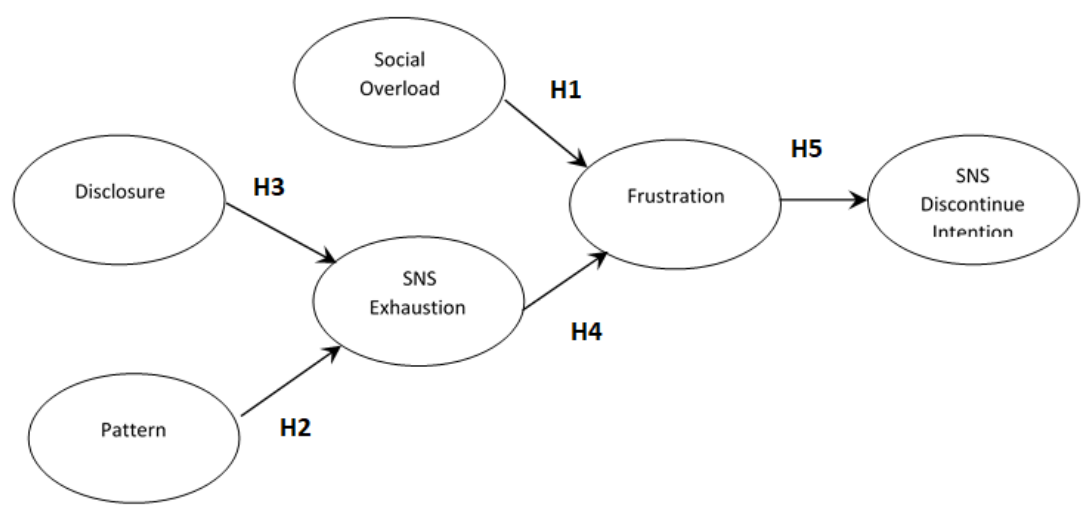

Figure 1. Research Model

\section{METHOD}

This research aims to show how discontinuous usage intentions are influenced. As Facebook is the most widely used and well-known SNS, and because research indicates that Facebook is a source and symbol of exhaustion and frustration [18], [19], [29], [33], we selected Facebook as the SNS for our experiment. All the experiment participants were Facebook users and thus aware of its pros and cons. The study was carried out by using a quantitative research method, whereby a survey questionnaire was distributed to the students of DIU University and we used the survey to evaluate the entire research model empirically. A 5-point Likert self-report instrument was adapted from previous researches as shown in Table 1, where all the items had adequate validity and reliability properties. The researcher used SmartPLS 3.0 software to analyse the findings of the study.

Table 1. Details of the instruments of the study

\begin{tabular}{ccc}
\hline Constructs & Number of Questions & References \\
\hline Social Overload & 5 & Adapted from: [18] \\
Pattern & 3 & Adapted from: [26] \\
Disclosure & 4 & Adapted from: [26] \\
SNS Exhaustion & 3 & Adapted from: [26] \\
Discontinuance & 5 & Adapted from: [18][32] \\
Frustration & 3 & Adapted from: [11] \\
\hline
\end{tabular}

\section{ANALYSIS}


A total of 170 questionnaires were distributed, and a total of 170 questionnaires were returned with a response rate of $100 \%$. The questionnaire consists of two sections; where demographic questions in first section, while the second section consist of items relating to the constructs.

Out of 170 respondents, $62.4 \%$ are male and $37.6 \%$ are female. Majority of the respondents $(44.6 \%)$ are from the age group category of $21-23$ years old. From the findings, $34.1 \%$ of respondents use SNS 6-9 hours in a day; and 54.1\% of users use Facebook 4-10 hours in a day nonstop. $63.53 \%$ of respondents do not have more than 1000 Facebook friends; and $45.88 \%$ use mobile to access SNS. Beside Facebook as SNS activity, respondents choose to use Whatsapp (16.47\%) as SNS activity.

To test the significance, path coefficients and the loadings were analyze using bootstrapping method at 5000 resamples as suggested by [34]. Validity and reliability of the measures were tested (Table 2); the composite reliabilities were all higher than 0.7 while the AVE were higher than 0.5 as suggested in the literature [34], [35]. The discriminate validity of the measures was examined by following the Fornell and Larcker criterion (Table 3) [35]. All the values on the diagonals were greater than the corresponding row and column values indicating the measures were discriminate.

Table 1. Convergent Reliability

\begin{tabular}{ccc}
\hline Components & Composite Reliability & Average Variance Extracted (AVE) \\
\hline Frustration & 0.896 & 0.742 \\
SNS Exhaustion & 0.806 & 0.583 \\
Disclosure & 0.746 & 0.521 \\
Discontinuation & 0.867 & 0.569 \\
Pattern & 0.819 & 0.601 \\
Social overloaded & 0.888 & 0.615 \\
\hline
\end{tabular}

Findings for the hypothesis testing shown in Table 4. The relationship between frustration on discontinuation $(\beta=0.136, p<0.05)$ are strongly significant which indicate H5 is supported. Findings also shown disclosure $(\beta=0.285, p<0.05)$ and pattern $(\beta=0.139, p<0.05)$ significantly influence SNS exhaustion small effect size of $\mathrm{f}^{2}$ values. Thus, H2, and H3 are supported. Social overloaded $(\beta=0.316, p<0.05)$ on frustration is strongly significant, and this $\mathrm{H} 1$ is supported, with small effect $\mathrm{f}^{2}$ values. Only H4 has no effect so that SNS Exhaustion on frustration is not supported. 
Table 2. Discriminate Validity

\begin{tabular}{ccccccc}
\hline Components & Frustration & $\begin{array}{c}\text { SNS } \\
\text { Exhaustion }\end{array}$ & Disclosure & $\begin{array}{c}\text { Discontinue } \\
\text { Intention }\end{array}$ & Pattern & $\begin{array}{c}\text { Social } \\
\text { overload }\end{array}$ \\
\hline Frustration & $\mathbf{0 . 8 6 1}$ & & & & \\
\hline $\begin{array}{c}\text { SNS } \\
\text { Exhaustion }\end{array}$ & 0.102 & $\mathbf{0 . 7 6 3}$ & & & & \\
\hline $\begin{array}{c}\text { Disclosure } \\
\text { Discontinuatio } \\
\mathrm{n}\end{array}$ & 0.167 & 0.398 & $\mathbf{0 . 7 2 2}$ & & \\
\hline $\begin{array}{c}\text { Pattern } \\
\begin{array}{c}\text { Social } \\
\text { overloaded }\end{array}\end{array}$ & 0.198 & 0.556 & 0.258 & $\mathbf{0 . 7 5 4}$ & & \\
\hline
\end{tabular}

Table 3. Hypothesis testing

\begin{tabular}{ccccc}
\hline Relationship & Effect size F & Path co-efficient & T value & Result \\
\hline $\begin{array}{c}\text { Frustration -> } \\
\text { discontinuation }\end{array}$ & 0.029, Small & 0.136 & 1.971 & Supported \\
\hline $\begin{array}{c}\text { SNS Exhaustion -> } \\
\text { Frustration }\end{array}$ & 0.002, No effect & 0.044 & 0.418 & Not Supported \\
\hline $\begin{array}{c}\text { disclosure -> SNS } \\
\text { Exhaustion }\end{array}$ & 0.077, Small & 0.285 & 3.490 & Supported \\
\hline $\begin{array}{c}\text { pattern -> SNS } \\
\text { Exhaustion }\end{array}$ & 0.020, Small & 0.139 & 1.942 & Supported \\
\hline $\begin{array}{c}\text { social overloaded -> } \\
\text { Frustration }\end{array}$ & 0.107, Small & 0.316 & 3.890 & Supported \\
\hline
\end{tabular}

From the Table 4, path co-efficient values of the specific relationship were drawn into a model as structural model of this study (Figure 2). 


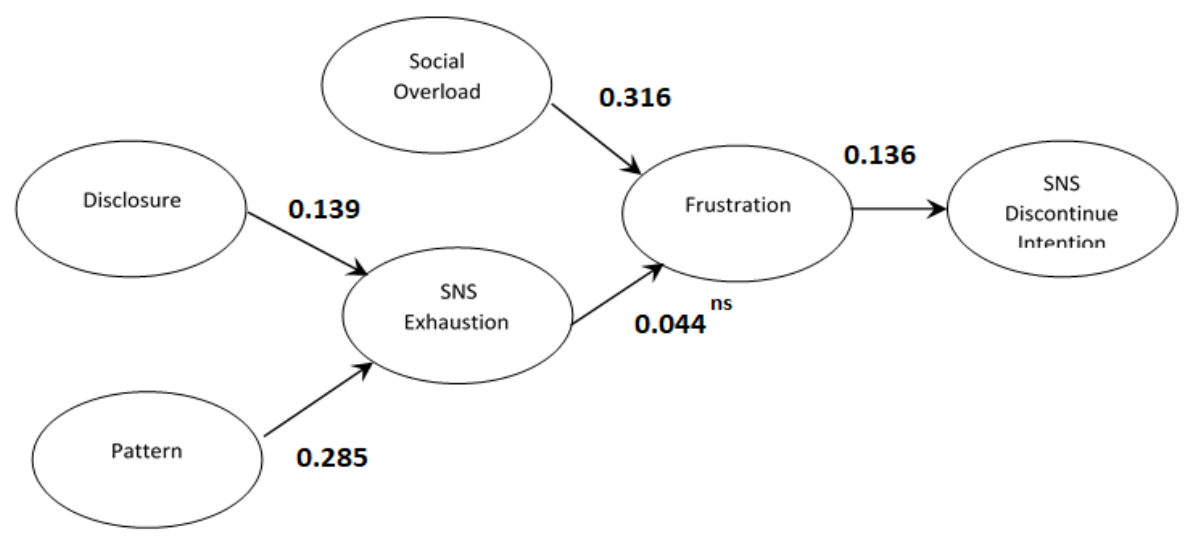

Figure 2. Structural Model with Result

\section{DISCUSSION}

Although much research has been performed on the phases of SNS frustration and then discontinuance, the final phase of termination has received little attention. This paper focuses on the development of discontinuous usage intention in the context of social networking services (SNSs), where it plays an especially crucial role. Furthermore, as discontinuing the use of an SNS also takes effort and has costs, we theorise that SNS exhaustion and frustration augment the intention to discontinue usage. In Bangladesh, 89.62\% people use Facebook as a social networking site. Facebook has a positive impact on techno-stress [29]. If SNS fails to fulfil the demands of the users, they then feel frustrated [36]. The findings revealed that a high level of SNS exhaustion induced a high level of intention to discontinue using an SNS [37]. The results from this study showed that frustration occurs when using SNS and leads to the intention of discontinued usage of Facebook. In addition, social overload was identified as an antecedent that influences frustration; while pattern and disclosure influence SNS exhaustion.

The results also demonstrated that social overload has small effect on frustration; disclosure and pattern have small effect on SNS exhaustion; and frustration has small effect on discontinuation. They hypothesised that 'the more an individual perceives social overload, the higher is the individual's emotional exhaustion' 'the higher an individual's satisfaction, the lower is the individual's discontinuous usage intention', and 'the more an individual perceives emotional exhaustion, the higher is the individual's discontinuous usage intention' [26]. This work contributes to the current theory in the area of technology acceptance. This study answered the call by Beaudry and Pinsonneault [3], to proof that frustration as a negative emotion has an influence on technology acceptance, and that emotions as antecedents cannot be neglected in IT behavior [38].

The results indicated that frustration has an effect on the discontinuation of SNS usage. Hence, SNS providers could try to provide alternative ways for SNS users to enjoy their SNS usage as well as beside reduce frustration. This is in line with the research conducted by other researchers who found out the antecedent of discontinued usage intention [3], [19], [32]. The SNS providers need to retain as many users as possible to determine the value of SNS in this world of technology [39]. The present research contributes to this stream of research by showing that the perceptions of 
exhaustion and frustration result in the development of discontinuous usage intentions, which are then subsequently translated into discontinuous usage. This suggests that when investigating adaptation strategies like SNS discontinuation, the SNS providers need to implement measures to ensure that the users do not perceive SNS-fatigue and also prevent their users from perceiving disclosure and social overload by implementing filter mechanisms. They also need to take good initiatives to stay connected with not only the existing users, but also attract new users with well-established GUI.

\section{LIMITATION AND FUTURE STUDY}

Several limitations should be acknowledged. First of all, the generalisability of this study is limited. It was only done in the context of Facebook. We were limited by the selection of participants and all of them did not respond properly. Hence, we received limited data from the desired respondents. The results might differ in case of a large sample size. More research involving other user segments and applications should be conducted for examining the boundaries of the research model and its generalisability. We focused on a limited number of factors. As young individuals like students comprise a large member group of Facebook, so we collected data from undergraduate students. Further research might repeat our study in organisational settings where SNS usage is mandatory. The results might vary depending on individual positions according to their social networking.

Future research may investigate if the results also fit in with other SNS activities such as the use of Instagram, YouTube, playing games and so on [40]. The research might use other constructs to determine the antecedents of frustration; beside further study on other negative emotions which might lead to discontinuous usage of SNS should be undertaken as well. Prior research indicates that discontinuous usage intention is suppressed by factors such as satisfaction. A research may examine what triggers the initiation and growth of discontinuance intent, and under what circumstances they become dominant and lead to actual discontinuance attempts. We also recommend that regarding exhaustion creator complexity, the providers should make their sites easy to use and provide training on a wide range of features. We recommend that future study should consider the influence of switching from one technology to another due to SNS frustration or exhaustion.

\section{CONCLUSION}

Our research model was built on the theoretical background that explained the SNS users' discontinuous usage intention and the corresponding discontinuous usage behaviour. Overall, social overload, pattern, and disclosure are strong antecedents for exhaustion and frustration; and frustration leads to considering discontinuing the usage of SNS sites, especially Facebook, as a consequence. Our proposed model was empirically tested and contributed to both SNS users and providers. We surmised that there are theoretically and practically interpretable relations among the antecedents and consequences of frustration, which require further investigation in a more exploratory way.

\section{REFERENCES}


[1] E.M. Rogers, Diffusion of Innovations: Modifications of a Model for Telecommuni cations, Springer Berlin Heidelberg, 1995.

[2] Bagozzi, R., Gopinath, M. and Nyer, P.U. (1999). The role of emotions in marketing. Journal of the Academy of Marketing Science, 27 (2), 184-206.

[3] Beaudry, A. and Pinsonneault, A. (2010). The other side of acceptance: Studying the direct and indirect effects of emotions on information technology use. MIS Quarterly, 34 (4), 689-A3.

[4] Lawson, R. (1965). Frustration: The Development of a Scientific Concept. MacMillan: New York.

[5] Kirschner, P. A., \& Karpinski, A. C. (2010). Facebook® and academic performance. Computers in human behavior, 26(6), 1237-1245.

[6] https://thenextweb.com/facebook/2013/10/30/facebook-passes-1-19-billion-mont hly-active-users-874-million-mobile-users-728-million-daily-users/

[7] Krasnova, H., Wenninger, H., Widjaja, T., \& Buxmann, P. (2013). Envy on Facebook: A hidden threat to users' life satisfaction?

[8] https://www.websitehostingrating.com/facebook-statistics/

[9] Sinha, D., \& Jaiswal, S. V. (2018). Use of social networking sites (SNS), social integration and social support in Indian medical students: a cross sectional investigation. International Journal of Research in Medical Sciences, 6(6), 20272031.

[10] Shpigelman, C. N. (2018). Leveraging Social Capital of Individuals with Intellectual Disabilities through Participation on Facebook. Journal of Applied Research in Intellectual Disabilities, 31(1), e79-e91.

[11] Ortiz, A. de Guinea, Titah, R. and Léger, P.-M. (2014). Explicit and implicit antecedents of users' behavioral beliefs in information systems: A Neuropsychological Investigation. Journal of Management Information Systems, 30 (4), 179-210.

[12] Pallud, J. and Elie-Dit-Cosaque, C. (2011). Extended vs. limited IT usage: The fault of users' emotions. AMCIS 2011 Proceedings, Paper 301.

[13] Li, H. and Sarathy, R. (2006). Exploring the impact of emotions on Internet users' perceived privacy. AMCIS 2006 Proceedings, Paper 121.

[14] Ethier, J., Hadaya, P., Talbot, J. and Cadieux, J. (2004). Business-to-consumer web site quality and web shoppers' emotions: Exploring a research model. ICIS 2004 Proceedings, Paper 72.

[15] Berger, K., Klier, J., Klier, M. and Probst, F. (2014). A Review of Information Systems Research on Online Social Networks. Communications of the Association for Information Systems, 35 (1), 145-172.

[16] Bright, L. F., Kleiser, S. B., \& Grau, S. L. (2015). Too much Facebook? An exploratory examination of social media fatigue. Computers in Human Behavior, 44, 148-155.

[17] Shokouhyar, S., Siadat, S. H., \& Razavi, M. K. (2018). How social influence and personality affect users' social network fatigue and discontinuance behavior. Aslib Journal of Information Management, 70(4), 344-366.

[18] Maier, C. (2014) Technostress: Theoretical foundation and empirical evidence.opus. urn:nbn:de:bvb:473-opus4- 256587.

[19] Maier, C., Laumer, S., Eckhardt, A., \& Weitzel, T. (2015). Giving too much social support: Social overload on social networking sites. European Journal of Information Systems, 24(5), 447-464. 
[20] Mcandrew, F. T., \& Jeong, H. S. (2012). Who does what on Facebook? Age, sex, and relationship status as predictors of Facebook use. Computers in Human Behavior, 28(6), 2359-2365.

[21] Moore, K., \& McElroy, J. C. (2012). The influence of personality on Facebook usage, wall postings, and regret. Computers in Human Behavior, 28(1), 267-274.

[22] Au, N., Ngai, E. W., \& Cheng, T. E. (2008). Extending the understanding of end user information systems satisfaction formation: An equitable needs fulfillment model approach. MIS quarterly, 43-66.

[23] Khan, Z. \&Jarvenpaa, S. L. (2010). Exploring temporal coordination of events with Facebook.com. Journal of Information Technology, 25, 137-151.

[24] Brandtzæg, Petter Bae. "Social networking sites: Their users and social implications-A longitudinal study." Journal of Computer-Mediated Communication 17.4 (2012): 467-488.

[25] Turel, O., \& Serenko, A. (2012). The benefits and dangers of enjoyment with social networking websites. European Journal of Information Systems, 21(5), 512-528.

[26] Maier, C., Laumer, S., Eckhardt, A., \& Weitzel, T. (2012). When Social Networking Turns to Social Overload: Explaining the stress, Emotional Exhaustion, and Quitting Behavior from Social Network sites' Users. In ECIS (p. 71).

[27] Tow, W., Dell, P. \& Venable, J. (2010) Understanding information disclosure behaviour in Australian Facebook users. Journal of Information Technology, 25, 126-136.

[28] Koroleva, K., Krasnova, H. and Günther, O. (2010). Stop spamming me! Exploring information overload on Facebook. AMCIS 2010 Proceedings, Paper 447.

[29] Luqman, A., Cao, X., Ali, A., Masood, A., \& Yu, L. (2017). Empirical investigation of Facebook discontinues usage intentions based on SOR paradigm. Computers in Human Behavior, 70, 544-555.

[30] Ayyagari, R., Grover, V., \& Purvis, R. (2011). Technostress: technological antecedents and implications. MIS quarterly, 35(4), 831-858.

[31] Sun, H. (2013) A longitudinal study of herd behavior in the adoption and continued use of technology. MIS Quarterly, 4 (37), 1013-1041.

[32] Turel, O. (2014) Quitting the use of a habituated hedonic information system: a theoretical model and empirical examination of Facebook users. European Journal of Information Systems. doi: 10.1057/ejis.2014.19.

[33] Chang, I.-C., Liu, C.-C.and Chen, K. (2014). The push, pull and mooring effects in virtual migration for social networking sites. Information Systems Journal, 24 (4), 323-346.

[34] Hair Jr, J. F., Sarstedt, M., Hopkins, L., \& Kuppelwieser, V. G. (2014). Partial least squares structural equation modeling ( PLS-SEM ) An emerging tool in business research. European Business Review, 26(2), 106-121.

[35] Fornell, C. and Larcker, D.F. (1981). Evaluating structural equation models with unobservable variables and measurement error. Journal of Marketing Research, $39-50$.

[36] Ravindran, T., Yeow Kuan, A. C., \& Hoe Lian, D. G. (2014). Antecedents and effects of social network fatigue. Journal of the Association for Information Science and Technology, 65(11), 2306-2320. 
[37] Maier, C., Laumer, S., Weinert, C., \& Weitzel, T. (2015). The effects of technostress and switching stress on discontinued use of social networking services: a study of Facebook use. Information Systems Journal, 25(3), 275-308.

[38] Koch, H., Gonzalez, E. and Leidner, D. (2012). Bridging the work/social divide: the emotional response to organizational social networking sites. European Journal of Information System, 21 (6), 699-717.

[39] Manago, A.M., Taylor, T. and Greenfield, P.M. (2012). Me and my 400 friends: The anatomy of college students' Facebook networks, their communication patterns, and well-being. Developmental Psychology, 48 (2), 369-380.

[40] Alzahrani, A. I., Mahmud, I., Ramayah, T., Alfarraj, O., \& Alalwan, N. (2017). Extending the theory of planned behavior (TPB) to explain online game playing among Malaysian undergraduate students. Telematics and Informatics, 34(4), 239-251. 
